\title{
Preparation and Properties of Doped Hg-Based Superconducting Copper Oxides
}

\author{
O. Babych*, Ya. Boyko, I. Gabriel, R. Lutciv, M. Matviyiv and M. Vasyuk \\ Electronics Department of Ivan Franko National University, Lviv, Ukraine
}

\begin{abstract}
Synthesis of $\mathrm{Pb}, \mathrm{Fe}$ and $\mathrm{Cd}$ doped $\mathrm{Hg}$-based $\mathrm{HgBa}_{2} \mathrm{Ca}_{2} \mathrm{Cu}_{3} \mathrm{O}_{8+\delta}$ ( $\left.\mathrm{Hg}-1223\right)$ superconducting ceramics was performed. $\mathrm{Hg}$-free precursor $\mathrm{Ba}_{2} \mathrm{Ca}_{2} \mathrm{Cu}_{3} \mathrm{O}_{8+\delta}$ with high chemical homogeneity and reactivity obtained by the sol-gel method was used. The superconducting and impurity phases were determined by means of scanning electron microscopy and microprobe analysis. The results of resistivity and magnetization measurements for different kinds of doped elements were presented.
\end{abstract}

PACS numbers: 74.72.-h

\section{Introduction}

The homologous series $\mathrm{HgBa}_{2} \mathrm{Ca}_{n-1} \mathrm{Cu}_{n} \mathrm{O}_{2 n+2+\delta}$ where $n=1,2,3 \ldots$ possesses the highest superconducting transition temperature $\left(T_{\mathrm{c}}\right)$ among analogous superconducting materials. Unfortunately, there are still scientific and applied problems concerning the phase stability, especially the presence of carbon dioxide and humidity. The doping with high-valence type $\mathrm{Re}, \mathrm{Pb}$ and another element has beneficial effects on both the phase stability and superconducting properties of the $\mathrm{HgBa}_{2} \mathrm{Ca}_{2} \mathrm{Cu}_{3} \mathrm{O}_{8+\delta}$ phase [1-3]. It was found that traces of moisture and/or carbon dioxide reduce the equilibrium mercury partial pressure $P_{\mathrm{Hg}}$ of nonsuperconducting phase $\mathrm{HgCaO}_{2}$, which is a product of the synthesis reaction, whereas partial substitution of Re, $\mathrm{Pb}$ and $\mathrm{Mo}$ for $\mathrm{Hg}$ suppresses the $P_{\mathrm{Hg}}$ of $\mathrm{Hg}-1223$ at the synthesis process [1]. In addition, it is known that the doping with numerous elements considerably influences the critical current of the high temperature superconductivity (HTSC) system of superconducting grains coupled by the Josephson weak links. For example, the pinning enhancement in the HTSC samples is shown to ocCur as a result of Fe ions influence on $\mathrm{Y}-, \mathrm{Bi}-$ and Hg-containing materials $[3,4]$.

Formation of the $\mathrm{Hg}$-based superconducting materials critically depends on the used precursor and synthesis conditions. Using the wet chemistry offers some advantages in comparison with the classical solid state ceramics processing, especially better chemical homogeneity and higher reactivity of the precursor powder. In particular, the solutions of oxalates, nitrates or organic complexes (sol-gel method) [5,6] were used for $\mathrm{YBa}_{2} \mathrm{Cu}_{3} \mathrm{O}_{7-\delta}, \mathrm{HgBa}_{2} \mathrm{Cu}_{1} \mathrm{O}_{4+\delta}$ synthesis processing.

In this paper, we report on the successful fabrication of $\mathrm{Pb}, \mathrm{Fe}$ and iSovalent $\mathrm{Cd}$ doped $\mathrm{Hg}$-based $\mathrm{HgBa}_{2} \mathrm{Ca}_{2} \mathrm{Cu}_{3} \mathrm{O}_{8+\delta}$ superconducting ceramics. The sol-

* corresponding author; e-mail: kafrem@electronics.wups.lviv.ua -gel method for preparing $\mathrm{Pb}, \mathrm{Fe}$ and $\mathrm{Cd}$ doped $\mathrm{Hg}$-free precursors was used. For determining the superconducting and impurity phases, scanning electron microscopy and microprobe analysis were used. The resistivity and magnetization of doped Hg-1223 were measured.

\section{Experimental}

The synthesis of $15 \% \mathrm{~Pb}, 5 \% \mathrm{Fe}$ and $5 \% \mathrm{Cd}$ by using the precursor method was performed. These levels of doping element contents were chosen from the viewpoint of optimum stability effect (for example [1], near $15-20 \% \mathrm{~Pb}$ ) and sufficient influence on the superconductive properties of $\mathrm{Hg}-1223$ (near $5 \% \mathrm{Fe}, \mathrm{Cd}$ ). Fine homogeneous and reactive $\mathrm{Hg}$-free precursor $\mathrm{Ba}_{2} \mathrm{Ca}_{2} \mathrm{Cu}_{3} \mathrm{O}_{8+\delta}$ samples were obtained by the sol-gel method using acetic acid as a complex-forming agent and the acetates of $\mathrm{Ba}$, $\mathrm{Ca}, \mathrm{Cd}, \mathrm{Cu}, \mathrm{Pb}$ and $\mathrm{Fe}$ were used.

The nanogranules synthesis from the supersaturated solution of these acetates in water-acetone solution (1:1) with ammonium citrate gel was carried out. The nanogranules growth in the range of $250-350^{\circ} \mathrm{C}$ was obtained. This material was pressed and annealed at flowing oxygen at $900^{\circ} \mathrm{C}$ for $120 \mathrm{~h}$.

The precursor was synthesized from oxides at the following thermal treatment $\left(\right.$ at $\left.900^{\circ} \mathrm{C}\right)$ :

$$
\begin{aligned}
& 2 \mathrm{BaO}+2 \mathrm{CaO}+2.95 \mathrm{CuO}+0.05 \mathrm{FeO}+0.15 \mathrm{PbO} \\
& =\mathrm{Pb}_{0.15} \mathrm{Ba}_{2} \mathrm{Ca}_{2} \mathrm{Cu}_{2.95} \mathrm{Fe}_{0.05} \mathrm{O}_{7+\delta} .
\end{aligned}
$$

The obtained precursor was milled along with $\mathrm{HgO}$ and pelletized at a pressure of $75 \mathrm{MPa}$. The pellets in sealed quartz tube were heated at $860^{\circ} \mathrm{C}$ for $30 \mathrm{~h}$ and furnace was cooled with $10^{\circ} \mathrm{C} / \mathrm{h}$.

Samples of $\mathrm{Pb}, \mathrm{Fe}$ and $\mathrm{Cd}$ doped $\mathrm{HgBa}_{2} \mathrm{Ca}_{2} \mathrm{Cu}_{3} \mathrm{O}_{8+\delta}$ superconductor were prepared in sealed quartz ampoules by means of the following reactions (on the example of $\mathrm{Pb}, \mathrm{Fe}$ doping):

$$
\begin{array}{r}
0.85 \mathrm{HgO}+\mathrm{Pb}_{0.15} \mathrm{Ba}_{2} \mathrm{Ca}_{2} \mathrm{Cu}_{2.95} \mathrm{Fe}_{0.05} \mathrm{O}_{7+\delta} \\
=\mathrm{Hg}_{0.85} \mathrm{~Pb}_{0.15} \mathrm{Ba}_{2} \mathrm{Ca}_{2} \mathrm{Cu}_{2.95} \mathrm{Fe}_{0.05} \mathrm{O}_{8+\delta},
\end{array}
$$




$$
\begin{array}{r}
0.85 \mathrm{HgO}+\mathrm{Pb}_{0.15} \mathrm{Ba}_{2} \mathrm{Ca}_{2} \mathrm{Cu}_{3} \mathrm{O}_{7+\delta} \\
=\mathrm{Hg}_{0.85} \mathrm{~Pb}_{0.15} \mathrm{Ba}_{2} \mathrm{Ca}_{2} \mathrm{Cu}_{3} \mathrm{O}_{8+\delta} .
\end{array}
$$

The precursor pellets and superconducting samples were examined for determining the composition of the superconducting and impurity phases by scanning electron microscopy and microprobe analysis.

The temperature dependences of the resistivity of $\mathrm{Pb}$, $\mathrm{Fe}$ and $\mathrm{Cd}$ doped $\mathrm{HgBa}_{2} \mathrm{Ca}_{2} \mathrm{Cu}_{3} \mathrm{O}_{8+\delta}$ ceramics after synthesis and annealing at $350{ }^{\circ} \mathrm{C}$ for $20-50 \mathrm{~h}$ in flowing oxygen and argon atmosphere were measured. The superconducting transition temperatures $T_{\mathrm{c}}$ (determined from the $\mathrm{d} \rho / \mathrm{d} T$ derivative) were presented. The magnetization versus temperature $(4.2-140 \mathrm{~K})$ and magnetic field (up to $15 \mathrm{kOe}$ ) measurements for different kinds of the doped elements using a Quantum Design PPMS device were carried out.

\section{Results and discussion}

According to the microscopy and microprobe analysis the used sol-gel method allows us to obtain fine homogeneous $\mathrm{Hg}$-free precursor (as seen in Fig. 1a for the example of Fe doping).

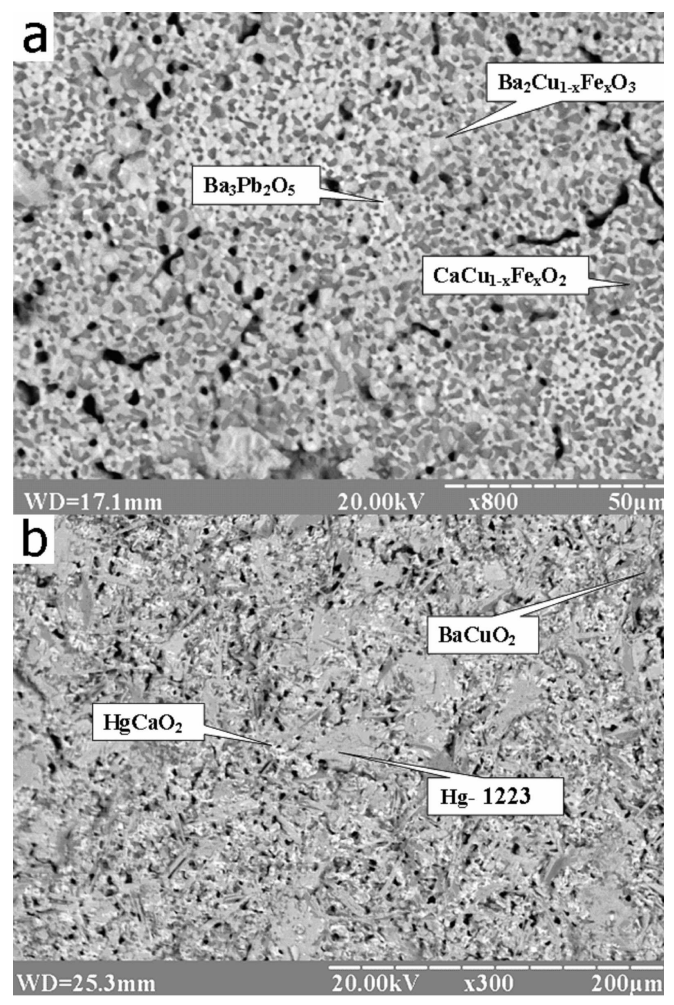

Fig. 1. Scanning electron microscopy (SEM) image of $\mathrm{Pb}_{0.85} \mathrm{Ba}_{2} \mathrm{Ca}_{2} \mathrm{Cu}_{2.95} \mathrm{Fe}_{0.05} \mathrm{O}_{7+\delta}$ precursor (a), $\mathrm{Hg}_{0.85} \mathrm{~Pb}_{0.15} \mathrm{Ba}_{2} \mathrm{Ca}_{2} \mathrm{Cu}_{2.95} \mathrm{Fe}_{0.05} \mathrm{O}_{8+\delta}$ (b).

There are three main phases in the precursor material: the grey granules of $\mathrm{BaCu}_{0.95} \mathrm{Fe}_{0.05} \mathrm{O}_{2}$, dark granules of $\mathrm{Ca}_{2} \mathrm{Cu}_{2.95} \mathrm{Fe}_{0.05} \mathrm{O}_{3}$ and white granules of $\mathrm{Ba}_{3} \mathrm{~Pb}_{2} \mathrm{O}_{5}$.

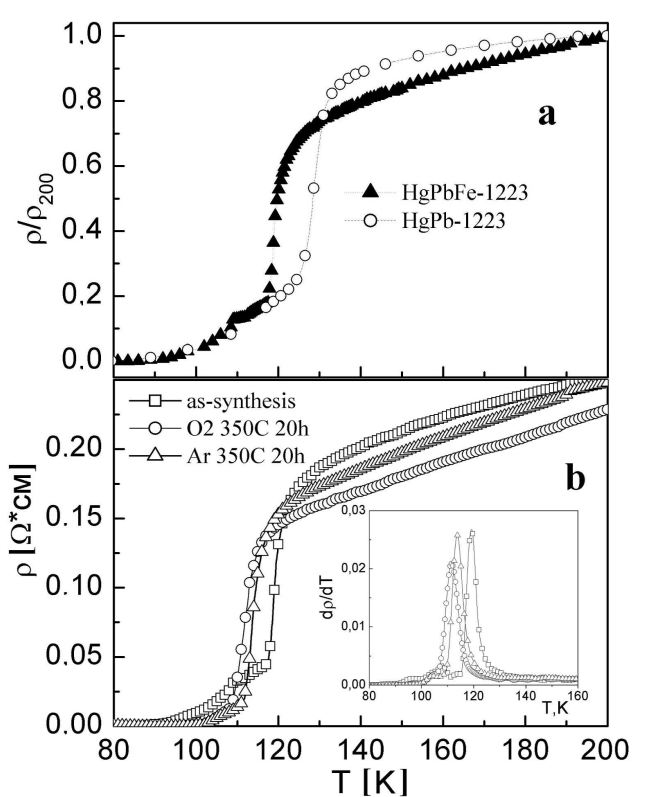

Fig. 2. Temperature dependences of resistivity: $\rho / \rho_{200}$ of $\mathrm{Pb}$, Fe doped $\mathrm{HgBa}_{2} \mathrm{Ca}_{2} \mathrm{Cu}_{3} \mathrm{O}_{8+\delta}$ as synthesized ceramics (a), and in flowing oxygen and argon for $\mathrm{Fe}, \mathrm{Pb}$ doped $\mathrm{HgBa}_{2} \mathrm{Ca}_{2} \mathrm{Cu}_{3} \mathrm{O}_{8+\delta}$ (b). In inset: $\mathrm{d} \rho / \mathrm{d} T$ versus temperature.

Figure 1b shows the typical picture of doped Hg-1223 ceramic surface. The superconducting phase is shown in Fig. 1 by the grey color. According to the microstructure analysis there are plate-like grains with a typical size of $10-20 \mu \mathrm{m}$. The $\mathrm{Hg}, \mathrm{Pb}, \mathrm{Fe}-1223$ material obtained by the sol-gel method possessed high density and nonsuperconducting phases such as $\mathrm{HgCaO}_{2}$ and $\mathrm{BaCuO}_{2}$ were observed. The formation of $\mathrm{HgCaO}_{2}$ by the interactions between $\mathrm{HgO}$ and oxides at $500{ }^{\circ} \mathrm{C}$ was achieved, however forming Hg-1223 phase was not observed. By the microprobe analyses it has been established that Fe is present in the superconducting phase near 5\%. Probably, Fe ions replace $\mathrm{Cu}$ in the $\mathrm{CuO}_{2}$ plane.

Figure $2 \mathrm{a}$ shows the temperature dependences of the resistivity of $\mathrm{Pb}, \mathrm{Fe}$ doped $\mathrm{HgBa}_{2} \mathrm{Ca}_{2} \mathrm{Cu}_{3} \mathrm{O}_{8+\delta}$ ceramics after synthesis and annealing in flowing oxygen and argon atmosphere (for the example of Fe doping, Fig. 2b). There are two-step dependences on the superconducting transitions. The low temperature part of the transitions is very sensitive to magnetic field and depends on the intergranular media. The values of $T_{\mathrm{c}}$ (determined at $\mathrm{d} \rho / \mathrm{d} T$ maximum) for $\mathrm{Pb}$ doped, $\mathrm{Hg}, \mathrm{Fe}, \mathrm{Pb}-1223$ samples were equal to $129 \mathrm{~K}$ and $118 \mathrm{~K}$, respectively. After synthesis the samples were in the oxygen overdoped state and reach the optimum state in flowing argon, similarly to the case of Fe doping. From Fig. $2 \mathrm{~b}$ we can see that $T_{\mathrm{c}}$ for the as-synthesized sample is $118 \mathrm{~K}$, while $T_{\mathrm{c}}$ decreases to $113 \mathrm{~K}$ at annealing in oxygen and grows up to $115 \mathrm{~K}$ in argon atmosphere.

The results of DC zero field cooling (ZFC) and (FC) magnetization $M$ measurement were shown in Fig. 3a. 

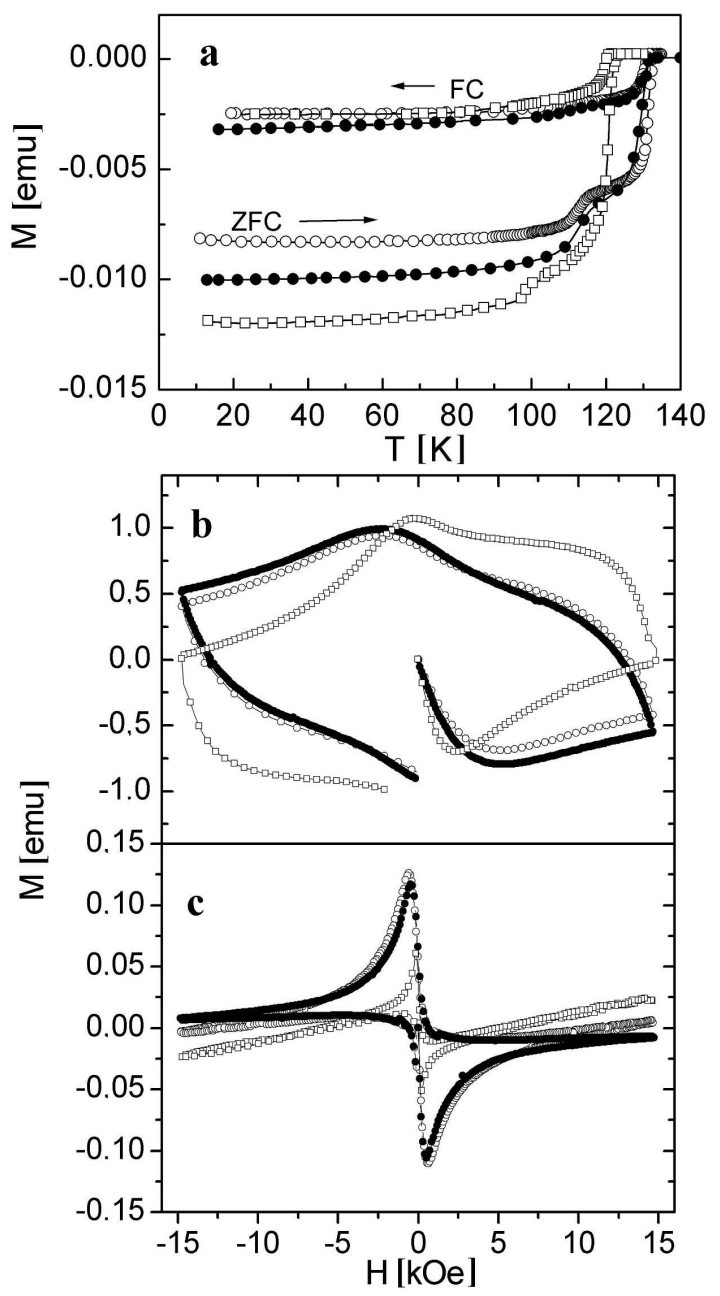

Fig. 3. Magnetization of $\circ \mathrm{Pb}, \square \mathrm{Fe}$ and $\bullet \mathrm{Cd}$ doped $\mathrm{HgBa}_{2} \mathrm{Ca}_{2} \mathrm{Cu}_{3} \mathrm{O}_{8+\delta}$ ceramics: versus temperature (a), in magnetic field at $4.2 \mathrm{~K}(\mathrm{~b})$, and at $77 \mathrm{~K}(\mathrm{c})$.

There are two-step dependences on the superconducting transitions which correlate with the electric measurements and $T_{\mathrm{c}}$ for the $\mathrm{Hg}, \mathrm{Cd}, \mathrm{Pb}-1223$ sample was determined at $126 \mathrm{~K}$. The magnetic hysteresis loops were measured at temperatures 77 and $4.2 \mathrm{~K}$ in applied field up to $15 \mathrm{kOe}$ for different kinds of the doped elements. The critical current at $77 \mathrm{~K}$ obtained from magnetization measurements has the same value for $\mathrm{Cd}, \mathrm{Pb}$ - and $\mathrm{Pb}$-doping and decreased for the $\mathrm{Hg}, \mathrm{Fe}, \mathrm{Pb}-1223$ ceramics. It was noted that the full penetration of magnetic field in the sample takes place at lower field values for $\mathrm{Hg}, \mathrm{Cd}, \mathrm{Pb}-1223$ in contrary to $\mathrm{Hg}, \mathrm{Pb}-1223$. This fact is connected with the decrease in the second critical field for $\mathrm{Hg}, \mathrm{Cd}, \mathrm{Pb}-1223$.

The intragranular critical current densities were estimated from magnetization measurement at $4.2 \mathrm{~K}$ (Fig. 3b) using the Bean model [7]. These are $J_{\mathrm{c}}-$ $6200 \mathrm{~A} / \mathrm{cm}^{2}$ for $\mathrm{Hg}, \mathrm{Pb}-1223$ and $\mathrm{Hg}, \mathrm{Cd}, \mathrm{Pb}-1223$. The doping of $\mathrm{Fe}, \mathrm{Pb}$ causes an increase of $J_{\mathrm{c}}$ to $6800 \mathrm{~A} / \mathrm{cm}^{2}$.

\section{Conclusions}

In this work, we carried out the synthesis of $15 \% \mathrm{~Pb}$, $5 \% \mathrm{Fe}$ and $5 \% \mathrm{Cd}$ doped mercury superconductor $\mathrm{HgBa}_{2} \mathrm{Ca}_{2} \mathrm{Cu}_{3} \mathrm{O}_{8+\delta}$ employing highly homogeneous and reactive $\mathrm{Hg}$-free precursor $\mathrm{Ba}_{2} \mathrm{Ca}_{2} \mathrm{Cu}_{3} \mathrm{O}_{8+\delta}$ obtained by the sol-gel method. The superconducting plate-like grains with a typical size of $10-20 \mu \mathrm{m}$ and nonsuperconducting phases of doped $\mathrm{Hg}-1223$ ceramics surface were observed. On the basis of temperature dependences of the resistivity of doped $\mathrm{HgBa}_{2} \mathrm{Ca}_{2} \mathrm{Cu}_{3} \mathrm{O}_{8+\delta}$ ceramics (on the example of $\mathrm{Fe}$ doping) it has been shown that after the synthesis the samples were in oxygen overdoped state and reach the optimum state in flowing argon.

The magnetization versus temperature $(4.2-140 \mathrm{~K})$ and magnetic field (to $15 \mathrm{kOe}$ ) for different kinds of doped elements was measured. The Fe doped samples of $\mathrm{HgBa}_{2} \mathrm{Ca}_{2} \mathrm{Cu}_{3} \mathrm{O}_{8+\delta}$ show decreasing $T_{\mathrm{c}}$, however, it gives rise to increase in the critical current in grain.

\section{References}

[1] Y.Y. Xue, R.L. Meng, Q.M. Lin, B. Hickey, Y.Y. Sun, C.W. Chu, Physica C 281, 11 (1997).

[2] R.L. Meng, B.R. Hickey, Y.Y. Sun, Y. Cao, C. Kinalidis, J.K. Meen, Y.Y. Xue, C.W. Chu, Physica $C$ 260, 1 (1996).

[3] W. Tian, H.M. Shao, J.S. Zhu, Y.N. Wang, Phys. Status Solidi B 196, 373 (2006).

[4] P.N. Togulev, V.V. Bazarov, I.B. Khaibullin, N.M. Suleimanov, Low Temp. Phys. 28, 250 (2002).

[5] K. Knizek, M. Veverka, E. Hadova, J. Heitmahek, D. Sedmidubsky, E. Pollert, Physica $C$ 302, 290 (1998).

[6] K.E. Levytska, T.A. Voitenko, S.A. Nedilko, Physica C 460-462, 722 (2007).

[7] C.P. Bean, Phys. Rev. Lett 8, 250 (1962). 